\title{
Correction to: The Effects of Social Class on Individuals' Decision-Making Tendencies in a Prestige-Money Game: Social Value or Instrumental Value?
}

\section{Pei Wang ${ }^{1}$ (D) $\cdot$ Chen-Hao Tan ${ }^{2}$}

Published online: 9 April 2019

๑) Springer Science+Business Media, LLC, part of Springer Nature 2019

\section{Correction to: Journal of Gambling Studies https://doi.org/10.1007/s10899-019-09827-2}

The original version of this article contained an error in the co-author name and e-mail address. The author name should read as "Chen-Hao Tan" instead of "Cheng-Hao Tang".

Publisher's Note Springer Nature remains neutral with regard to jurisdictional claims in published maps and institutional affiliations.

The original article can be found online at https://doi.org/10.1007/s10899-019-09827-2.

Pei Wang

wangpei1970@163.com

Chen-Hao Tan

tch9235@163.com

1 Faculty of Education, East China Normal University, 3663 Zhongshan North Road, Putuo District, Shanghai 200062, China

2 Department of Psychology, Shanghai Normal University, 100 Guilin Road, Xuhui District, Shanghai 200234, China 